\title{
A NEW CHALCIDOID OF THE EULOPHID GENUS APHELINUS DAL- MAN, PARASITIC ON SCHIZONEURA CRATAEGI OESTLUND.
}

By A. ARSÈne GiRAUlt, URBANA, ILlinois.

Family EULOPHIDÆ.

Subfamily ApHelininae.

Tribe Aphelinini.

Aphelinus varicornis species nova.

Normal position.

Female:- Length, $1.24 \mathrm{~mm}$., avg. Moderately large for the genus. Same in general coloration, stature and sculpture as Aphelinus mali (Haldeman), but differing in the following italicized details: Fore wings with a distinct fuscous patch under the marginal vein, more pronounced immediately caudad of the stigma, especially seen as a round dot at the stigma, the fuscous area quadrate and extending distinctly caudad to the middle of the wing where it is evanescent; caudal femora white, not sordid yellowish, basal joint of caudal tarsi blackish, cephalic and intermediate femora fuliginous, the knees and the intermediate and caudal trochanters white, the cephalic tibiae white clouded with dusky and the remaining tibiae sooty black, yellowish at their extremities; apical tarsal joints sooty; antennae variable, varicolored, the scape, pedicel and first two funicle joints sooty, the two basal joints of the funicle, however, with some yellowish; the apical funicle joint and the club chrome yellow, the latter often paler yellow; ventum sooty black; area of the fore wing proximad of the oblique hairless line also naked, but with no setae beneath the marginal vein as in mali, excepting one or two, and with but 2 transverse (caudo-proximal) lines of setae along the proximal border of the oblique hairless line; the proximad of these two lines of setae runs not quite to the center of the wing. Tip of the abdomen concolorous. Hind wings densely ciliate discally.

Shining black: Whole of thorax very delicately sheened, the mesopostscutellum acute along the meson; eyes hairy, deep purplish red, just after death imperial purple; ocelli deep ruby red, the lateral ones some distance from the eye margin, and widely separated, being about 5 times farther from each other than each is from 
the eye margin and about one-fourth farther apart than each is from the cephalic ocellus and on or very near the occipital margin; proximal segment of the abdomen sordid yellowish. Pubescence of head and thorax black. Proximal intermediate tarsal joint longer than the combined length of the two next joints following. Submarginal vein narrow, dark, the marginal broader, pallid yellow.

Antennae 6-jointed, the scape short and slightly dilated, nearly as long as the funicle and pedicel combined, or twice the length of the pedicel; the latter obconic, slightly longer than the third funicle joint, or over half the length of the funicle; joints 1 and 2 of the funicle like ring-joints, subequal, joint 2 larger, both about onethird narrower than the pedicel and combined not as long as the third funicle joint, which is quadrate-oval and as wide as the unjointed club. The latter longest, subequal to the scape and longer than the funicle, ovate. Antennae inserted below the middle of the face, with very few hairs.

Mandibles quadrate-rectangular, bidentate, the outer (lateral) tooth short and moderately acute, triangular, the inner (mesal) one longer, four times broader and broad and truncate.

(From 20 specimens, $\frac{2}{3}$-inch objective, 2-inch optic, Bausch and Lomb.)

Male:- Unknown.

Described from 20 females reared from November 16 to December 18, 1908, by Mr. John J. Davis in the insectary of the office of the State Entomologist of Illinois, from about the last three stages of the viviparous females of Schizoneura crataegi Oestlund on Crataegus, Chicago, Illinois. The hosts were collected on October 17th, 1908, in Garfield Park, by which date nearly all of the parasites had emerged; 13 of the specimens obtained emerged in the insectary at Urbana between November 16 and December 10, 1908, and the remaining 7 specimens between the latter date and December 18, 1908. The description was made from specimens mounted in xylol-balsam, tag-mounted and from living specimens stupefied with chloroform.

This species is very closely allied to Aphelinus mali (Haldeman) both in habits, structure and coloration and is very probably a variety of it, but until that point is settled by careful breeding, both expediency and progress demand that it should be given a name, and between the two grades of species and variety, I prefer to place it in that of the former, as being the less hazardous of the two.

Hosts parasitized by this parasite change to a deep pruinose blackish color and become considerably swollen and the caudal part of the abdomen is slightly elevated above the surface; the parasites are solitary and issue usually from circular holes in the dorsal or dorso-lateral aspect of the proximal end, or of the center, of the abdomen of the host; some of the emergence holes are, however, jagged and irregularly elongate. 

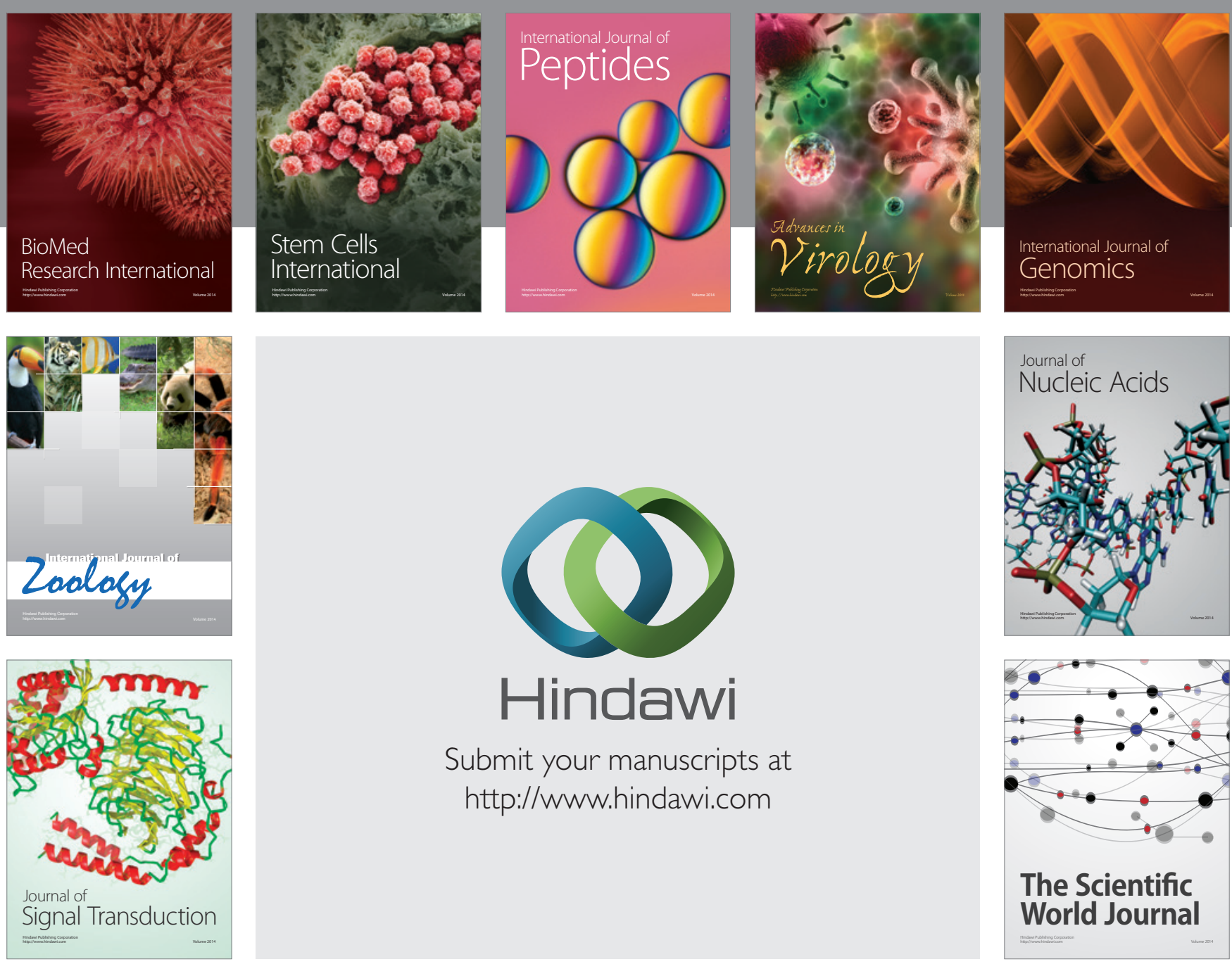

Submit your manuscripts at

http://www.hindawi.com
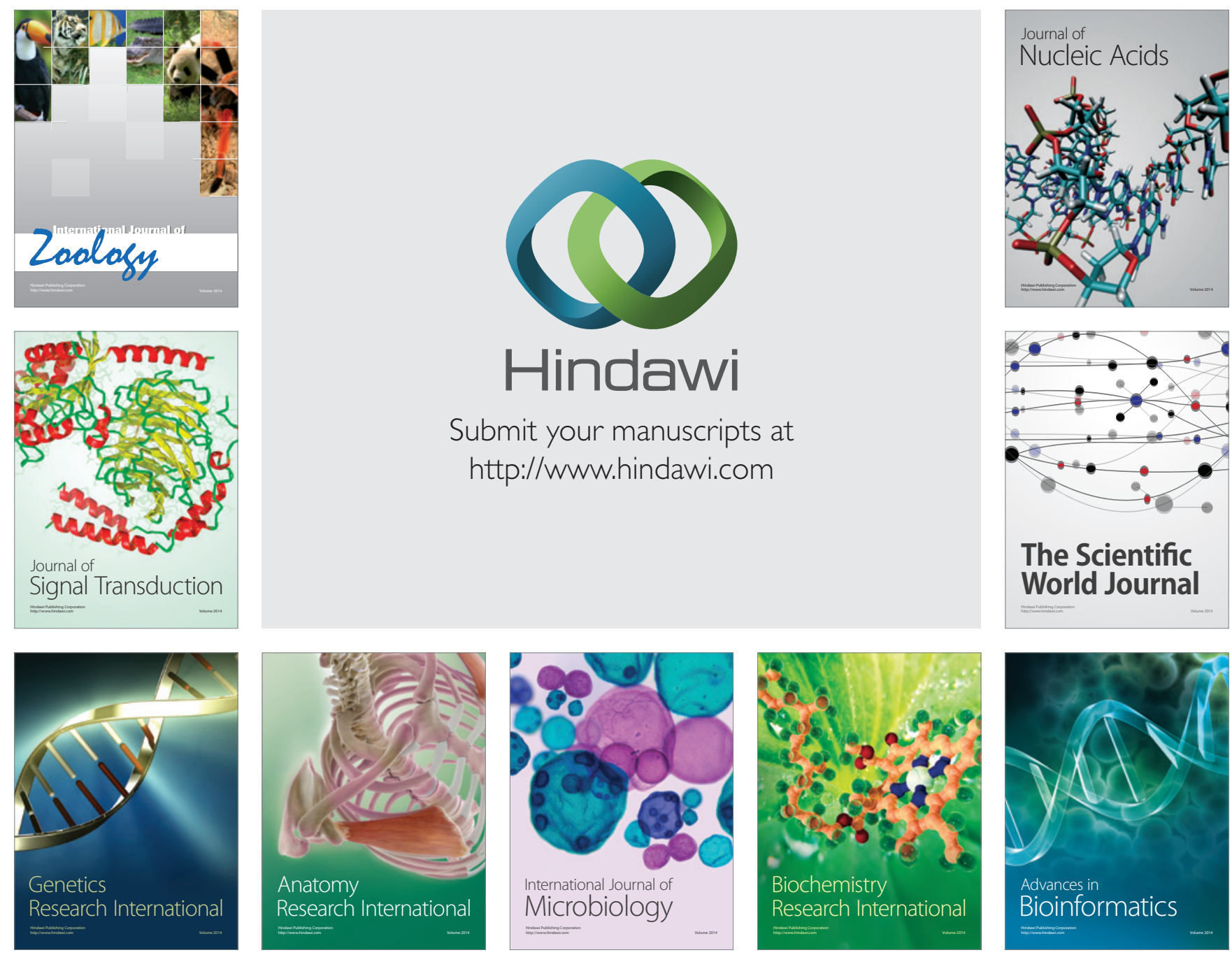

The Scientific World Journal
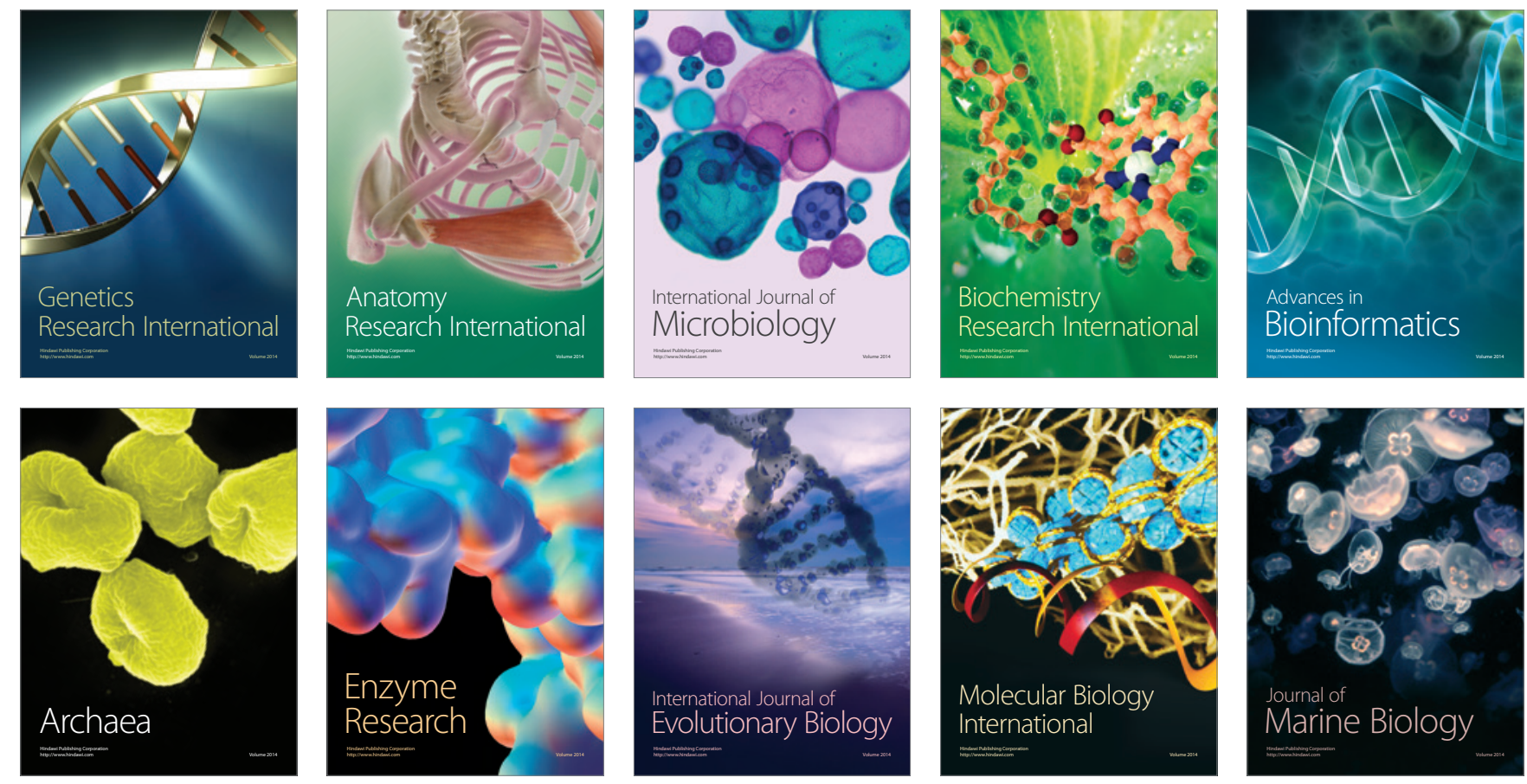